\title{
Gamification of a Procurement Process for Professional Training of Public Servants
}

\author{
Maksims Kornevs ${ }^{1}$, Jannicke Baalsrud Hauge ${ }^{2}$, Sebastiaan Meijer ${ }^{1}$ \\ ${ }^{I}$ School of Engineering Sciences in Chemistry, Biotechnology and Health \\ KTH Royal Institute of Technology, Stockholm, Sweden \\ \{kornevs, smeijer\}@kth.se \\ ${ }^{2}$ School of Industrial Engineering and Management \\ KTH Royal Institute of Technology, Stockholm, Sweden \\ jmbh@kth.se
}

\begin{abstract}
Implementation and training about changes in a procurement process are complex due to the complexity of the procurement process characterised by the adaptive stakeholder network and continuously changing market rules. Traditional training approaches for procurement split the process into separate steps; however, to be able to assess all training aspects, it is important to have a holistic look at procurement. This work explores how well gamification can address the complexity of the procurement process for training specialists in the road construction sector. A case study is carried out to train new business models for both experienced specialists and new employees. The steps for the development of gamification for training in procurement are shown. A comparison of results from experienced and less experienced participants is presented. The results show the relationships amongst the complexity of the real system, the gamification design and the results of gamification.
\end{abstract}

Keywords: Gamification, Employees' training, Public sector, Game culture, Procurement strategies;

\section{Introduction}

Within the public sector, a procurement process is used for obtaining services, work or products according to the specifications [1][2]. This process is in most cases essential for the quality of the service of public organisations in fields like construction projects, information system projects, energy or hydro projects, healthcare, etc. [3-5]. However, the procurement process is complex and often explicitly tailored for different projects [6][7]. Hence, when changes are required to be made in concordance with how the procurement process is carried out within each organisation, it is crucial that all parties involved in the process understand every step and all changes correctly [8]. This is not a trivial task due to the complexity, the highly bureaucratic nature of the procurement process and difficulties in assessing the outcomes of potential changes in the process.

Despite the importance of the procurement process, there is little research on what successful change management of the entire procurement process should look like. Even though most of the current studies suggest dividing the procurement process into separate steps and focusing only on specific parts [8-11], a holistic view is important for a proper assessment of the outcome of the change management activities of the procurement process [12]. For this reason, this work uses gamification of the procurement process for the whole procurement process without dividing it into parts. 
Hence, this work assesses how well gamification can be used for training of complex processes such as the procurement process and presents the outcome of gamified training sessions.

Based on the purposes of this work, several outcomes can be achieved. First of all, it shows the steps in how the procurement process can be gamified as a whole complex system with influence on the market and network of stakeholders. Secondly, this work presents how gamification of the procurement process helps to investigate the difference between experienced specialists and new employees in the field and the role of experience as an opportunity for organisations to widen and deepen their knowledge on their employees. Thirdly, the connection between the results of the gamification of training and the effects of different aspects that contribute to the complexity of the real system is described. Lastly, this work shows how even a few successful gamification applications in an organisation helps to build interests in game culture and helps employees to see the potential benefits of gamified experiences.

The work is organised as follows: in Section 2, we provide a background on project procurement with some issues with the procurement process. Section 3 describes how the procurement process was gamified and in Section 4 we provide the results obtained from the case study. Section 5 includes a discussion based on the results. Finally, we conclude the paper in Section 6.

\section{Background}

Every year services, works and supplies worth $15-20 \%$ of the global GDP are obtained using a procurement process [13]. In many fields, such as energy production and consumption, transportation, waste management, healthcare, and social care, government institutions are the main buyers, and hence they are required to use a procurement process [5].

Procurement is a process of obtaining products, services or works. Many public organisations are legally obliged to follow this process [1]. Procurement aims at getting the best results for the money while treating all suppliers in a similar and nondiscriminatory way. The procurement process includes a needs analysis for procuring goods, services or works, production of enquiry documentation, advertising, tender evaluation and awarding [13].

\subsection{Types and forms of contracts}

Although all procurement contracts follow similar steps, there are different types of procurement contracts. These types depend on the purpose of the contracts, market structure, requirements and specifications and other factors that have to be supported during the procurement process [14].

Procurement contracts differ in their design specifications for the final products, services or works. Based on the level of involvement of the supplier and the buyer in the specification stage, procurement contracts can have different forms. Contracts can vary from being fully detailed specifications by the buyer to being joint specifications [15].

Procurement contracts can have different compensation forms. Based upon the procurement arrangement, the procurement contract can be a fixed-price contract, costreimbursable contract, or a time and materials contract [16]. These contracts have different risk levels, project cost transparency and difficulty of project management.

Another difference in procurement contracts relates to the selection criteria and award criteria for each procurement contract [17]. Selection criteria help to filter suppliers who can take part in the bidding process. Usually, such criteria would include requirements on experience, size of the organisation or financial statements. Awarding criteria specify how the evaluation of received bids happens. Often contracts are awarded based on the lowest price, but in some cases, contracts are awarded based on the set of criteria that are 
important for the buyer: bid price and soft parameters, for example: innovation, sustainability, the environment and others.

Another important aspect of the procurement process within the organisation is the level of standardisation of procurement contracts [18]. Depending on the objective of the procurement process, some contracts can be harder than others. Typically, obtaining products or goods can be highly standardised in organisations, while a procurement process that is based on a unique project requires more activities to ensure proper project execution. Most organisations are using business models as a set of guidelines to help to determine how the procurement process needs to be performed.

Choices related to types and forms of procurement contracts affect the degree of freedom that suppliers have during the project execution. These choices have to be in balance with budget constraints and market offers. When this balance is not reached, it leads to issues with the degree of freedom. Low degree of freedom for suppliers is caused by over-specification and leads to even lower innovation level, less interest from the market and less efficiency of the project in general [19]. On the other hand, a high degree of freedom often leads to a too vague interpretation of the project and poor integration with an existing solution or infrastructure, and often misses some of the goals within the project.

\subsection{Stakeholders in public procurement}

An essential condition for a successful realisation of the procurement is proper coordination between the internal and external stakeholders involved in the procurement process. Typically, internal stakeholders are, but not limited to, project managers, procurement specialists, strategists, internal regulation developers, in-house experts, etc. At the same time, the procurement process is controlled by other organisations as well. They can be state law enforcement and supervising authorities, NGOs, consultants and potential suppliers as well.

Although the procurement procedure can affect a number of tenders (open procedure attracts more tenders, while limited procedure allows fewer tenders to participate), the procurement process is still collaboration between different stakeholders. The coordination between all these stakeholders is complicated because they often have different objectives and strategies [20]. It creates an adaptive stakeholder network, where requirements are adapted to satisfy the needs of all stakeholders as much as possible [21]. An adaptive stakeholder network can lead to a number of issues, such as distributed control in the network, contradicting goals and information asymmetry. These issues lead to uncertainties in contracts.

Uncertainties occur in situations when some information is unknown or is known just partially. Some of the uncertainties are concerned with the methods or tools that are used [6]. Lack of experience and limitation of methods and tools increase the uncertainty level and make it harder to fulfil all the goals of the project. Another source of uncertainty relates to uncertainty concerning the objectives and scope of the project. This is often caused by contradicting specifications, standards or regulations, by changes in the requirements or by misinterpretation of the contract. This type of uncertainty can lead to delays, or to cause some works not to be completed or to be performed more times.

\subsection{The complexity of the procurement process}

Variety in decision making related to the procurement process and final types and forms and high correlation between stakeholders cause the majority of project procurements to be complex [22][23]. Complexity also is related with the technologies and the environment of the work: systems are often technically advanced and interact with other systems and with human users, or work needs to be done in extreme environments and is accompanied by high risk [24]. 
To achieve the best results from the procurement process, the degree of freedom, uncertainties and complexity in a project need to be addressed in a holistic manner. This means that a problem has to be addressed in its entirety, including the social component (interaction between stakeholders) and the technical component (business models related to types and forms of procurement contracts). This can be achieved by using participatory methods because of their strong focus on human behaviour [20]. One of such methods that deal with changes related to procurement processes is gamification [25].

\section{Gamification of employee training}

Despite the growing interest in gamification in recent years [26], there are still different opinions on what gamification is. Definitions of gamification vary from a process of developing games where the final results of gamification are a simulated environment [27], to use of game design elements in a non-game context [28]. However, most of the existing works agree that the purpose of gamification is to apply lessons from a game or gamified experience to change the behaviour of players in the real world [29]; and most gamification applications reward participants who behave in a certain way using points, badges and leaderboards to boost good behaviour [30-33].

At the same time, gamification receives a share of criticism for overusing these game elements and missing the real complexity that exists in the system. Many gamification examples add some game elements to an actual process to create an illusion of gamified experience rather than investing in a proper design process [34]. Another criticism of gamification comes from its role in the game culture of an organisation. Many participants are interested in gamification because of its novel approach to issues, but it does not have a long-lasting impact on the organisation [35]. Gamification in big companies often also is not successful because of the hierarchical structure of the organisation, which makes it hard to engage participants from all levels and to make them open to gamification and to the changes that gamification brings [25]. Also, some processes in organisations are more challenging to gamify. So, gamification of bureaucratic processes often fails because of failure to perform a full analysis of the complex procedures with unclear borders and responsible persons [36].

Hence, to ensure a successful design of gamification of training for a big organisation for a bureaucratic process, proper training needs must be addressed. This can be done using the three phases suggested by Surface [37]. He recommends starting with needs identification and determining if there are needs in the first place and if there is a value for the organisation to address these needs. The second step is the needs specification. During this phase, it is essential to define what causes the gap between the current state and the desired state. Such a gap can be a lack of knowledge, skills, motivation, or flexibility in the process flow. Some potential solutions must be identified. The third phase is training itself with evaluation and, if needed, a further modification of training.

\section{Implementation of new business models}

The Swedish Transport Administration had identified the need to make changes in their procurement strategies to improve the quality of their projects by having better work relationships with the suppliers. To achieve this, the Administration had decided to use new business models for project procurement. These models were developed to assist the decision making on what type of procurement strategy is the best to apply for each project [38]. The main idea behind the models was that the collaboration form between the Transport Administration and service suppliers is determined based on the level of complexity, the degree of freedom and uncertainties. A simplified version of the models can be seen in Table 1. Fifteen models were developed to work with procurement for road 
designing, road construction procurement and road maintenance procurement. Each model suggested the contract form, compensation form, procurement procedure, awarding criteria and collaboration form based on the predicted level of complexity, the degree of freedom and uncertainties for a specific project.

Table 1. Components of Business Models for Procurement based on Collaboration Focus, based on [38]

\begin{tabular}{|c|c|c|c|}
\hline & Competition focus & \multicolumn{2}{|c|}{$\langle>$} \\
\hline Contract form & $\begin{array}{c}\text { The detailed } \\
\text { specification by the } \\
\text { buyer }\end{array}$ & $\begin{array}{l}\text { Joint specification } \\
\text { with customer } \\
\text { responsible }\end{array}$ & $\begin{array}{c}\text { Joint specification } \\
\text { with shared } \\
\text { responsibility }\end{array}$ \\
\hline Compensation form & Fixed price & Cost-reimbursable & $\begin{array}{l}\text { Cost-reimbursable } \\
\text { with bonus options }\end{array}$ \\
\hline $\begin{array}{l}\text { Procurement } \\
\text { procedure }\end{array}$ & Open, many tenders & Limited, few tenders & $\begin{array}{l}\text { Direct negotiation } \\
\text { with a supplier }\end{array}$ \\
\hline Awarding criteria & Lowest price & $\begin{array}{l}\text { Both price and other } \\
\text { parameters }\end{array}$ & Other parameters \\
\hline Collaboration form & $\begin{array}{c}\text { No collaborative } \\
\text { activities }\end{array}$ & $\begin{array}{c}\text { Some collaborative } \\
\text { activities }\end{array}$ & $\begin{array}{c}\text { Multiple collaborative } \\
\text { activities }\end{array}$ \\
\hline
\end{tabular}

The current procurement process implies that procurement specialists are in charge of making the decisions regarding the procurement process for each project. Although it is recommended that project leaders and procurement specialists work together, in reality, this happens very rarely. Most commonly, a procurement specialist receives a project description with the description of an object, works that need to be done, technical and functional specifications and project goals. To be able to apply new business models, the procurement specialist has to decide the level of complexity, the degree of freedom and uncertainties based on these documents. When the procurement specialist has chosen the most appropriate business model, he or she produces all the necessary procurement enquiry documentation.

To help procurement specialists to know better how to use these new business models, the Swedish Transport Administration developed a series of training sessions. As part of these sessions, the Administration decided to use gamification for training employees to create an environment where procurement specialists can test how to apply new business models.

\subsection{Training needs assessment}

To assess the needs of training on new business models, Surface's steps [37] were implemented as explained in chapter 3.

During the first step of needs identification, the role of the new business model was evaluated as a part of the change process to determine if the change was significant enough to focus training on it. Since the use of the new model affects contracts for the majority of road-related procurement by the Swedish Transport Administration, proper use of the models can help to save money for the organisation. At the same time, some of the aspects of the model are complicated and training can help to improve the right implementation of the models.

When the need was identified, a gap between the current state and the desired state had to be specified to determine it. Closer examination of the models showed that most of the challenges were in determining the right level of complexity, the degree of freedom and uncertainties. Another challenge was related to motivation to implement long-term strategies in the procurement process.

After the needs specification, training was planned. In the case of training for the procurement process, the Swedish Transport Administration had identified the goals of the training as $(i)$ a need to apply business models based on project descriptions that are provided to procurement specialists, (ii) a need to analyse the provided documentation to 
pag. 28

perform a proper assessment, and (iii) a wish to apply the strategic goals of the organisation while performing daily operations. To achieve these goals, the gamification included all the steps that players would be involved in in the real world while working with the procurement process.

\subsection{Experimental set-up of gamified training}

To ensure the best experience for the participants, the gamification was designed to be as similar to the existing procurement process as possible [32]. The training process can be seen in Fig. 1. The process started with providing typical project documentation to teams of participants. The participants were asked to produce a procurement contract based on the documents according to the new business models and strategies of the organisation.

Once participants had completed their procurement contracts, their work was evaluated by experts. The choice of business model and additional changes were analysed and participants received feedback and scores based on their choices.

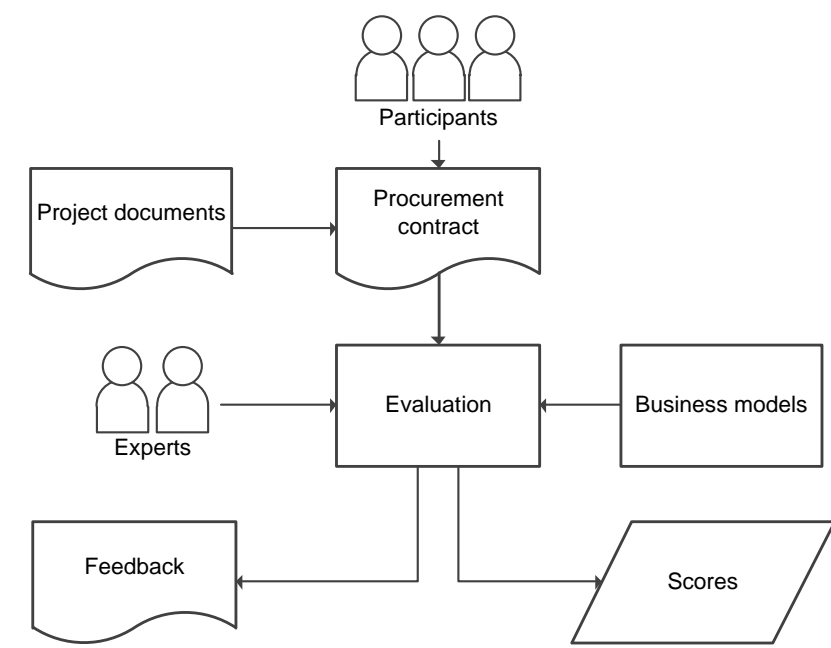

Figure 1. Gamification of the procurement process

While the training's intention was to learn to apply new business models based on documentation, gamification was used with the intention to engage trainees in the process: the bureaucratic nature of the procurement process makes it hard to engage people in working extra with this type of documentation.

\subsection{Cases}

The Swedish Transport Administration selected the three most used types of contracts, which were procurement for road designing, road construction procurement and road maintenance procurement. Experts from the procurement strategy unit of the Administration who developed these business models developed a project description for each contract. The aim was to have a realistic contract that has all the necessary information to make a deliberate choice but at the same time, not be too trivial, which means some information could be missing or incomplete.

The training session was based on three cases, where the participants needed to procure all three types of contracts. The contracts were not connected, and outcomes did not affect the following cases.

\subsubsection{Case 1}

The first case was about using business models for procurement of road designing. Participants were given documentation for work in a fictional area: a map of the area, and a mission statement that contains a description of the object and an assignment. 
Participants also received a list of file names for technical elements. This list did not contribute to a better understanding of the situation; however, it did contribute to the more realistic environment.

Participants were instructed to fill out a request for tender based on their best understanding of business models and keeping in mind the strategic goals of the organisation. They were encouraged to be creative in aspects that did not contradict business models.

After all teams presented their results, a brief discussion was held to compare the results and address some questions regarding both training and business models. Also, during this discussion participants were asked to reflect on how this experience was relevant to their daily work.

Although this case was used in training for a proper business model, it served more as an introduction to the rules and objectives. This choice was related to the fact that the business strategies for this type of procurement were not different from the already existing strategies that were used for the procurement of road designing.

\subsubsection{Case 2}

The second case was about using business models for road construction procurement. The work was for another fictional area. Two documents were given to participants during this case - a map of an area and a project specifications report. This seventeen-page document described the results of the needs analysis, the scope of the project, implementation steps, a risk analysis and financial aspects. This form was an internal description of the project that was often used in the organisation.

Again, participants were told to fill out a request for tender based on a proper business model while not forgetting about the strategies of the organisation. After the exercise, their work was discussed.

\subsubsection{Case 3}

The third, and the last, case was about road maintenance procurement. Three documents were given to participants that contained information about yet another fictional area with a description for a maintenance road and a table with work amounts.

Similar to previous cases, participants were instructed on what to do and then it was followed by a more significant discussion that was focused on the results from all cases.

\subsection{Participants and setup}

Participants for the training were selected from road procurement specialists who worked for the Swedish Transport Administration. This led to having a small, but valid, set of participants with eight high-level specialists and eight new employees. The high-level specialists had many years of experience both in the Swedish Transport Administration and in the private sector. The new employees were a less experienced group who only started working in road procurement. Participants were divided into eight teams of two players. Specialists and new employees played separately from each other to reduce authority bias.

Each training session started with an introduction to the new business models and description on how to apply them. This was followed by playing each case. Players were instructed on the objectives and flow of each case. They had one hour to read the project description and to make a decision about the business model they were planning. They also could make any other changes during this time. After each case, a 15-minute debriefing was held to discuss the decisions that players made. When all three cases were completed, a more extended debriefing was focused more on the experience gained during the training. 
pag. 30

\subsection{Gamification elements}

Gamification elements in training encourage players to have a friendly competition and motivate participants to learn. Scores and leaderboards are used to improve skills to apply business models based on project descriptions that are provided to procurement specialists. Additionally, immediate real-time feedback provided in the form of short debriefing sessions after each of the cases supported players in their analysis of documentation. Extra points are also used as motivation to determine the winning player in cases of even scores for business strategy. Plus, gamification provides needed reinforcement and support to players by adding elements of engagement and fun to the training process.

\subsection{Scoring}

Scoring was used as a mechanism to ensure that all goals of the training were achieved. Since the main purpose of the training was to address the need to apply business models based on project descriptions, each team could receive points for choosing the right contract form, compensation form, procurement procedure, awarding criteria and collaboration form based on each procurement task description. For each right category, the team received up to two points. It is important to notice that most of the categories were defined by a number of fields that participants had to fill out, and it was important to evaluate scores based on the entire document and not merely on a few steps.

Another purpose of the training was to encourage participants to apply the strategic goals of the organisation while performing daily operations. It was a minor goal, and therefore it affected scoring only a little: teams could get some extra benefits for implanting general strategies of the organisation in their work, such as increasing innovation, transparency, sustainability, life-cycle costs, etc. However, this extra work gave no more than one point in total and issued mainly to compare participants who got the same scores based on the business model.

In total, participants could get a maximum of 11 points in each case.

\section{$5 \quad$ Results}

The results of the gamification of the procurement process for professional training of public servants were based on the scoring and the debriefing.

Scores that players received for choosing the right business model and extra points for changes based on the strategic plan of the organisation were compared across cases and teams to analyse the results of the gamification for the training. The results are presented in Table 2.

Table 2. Scores of each team

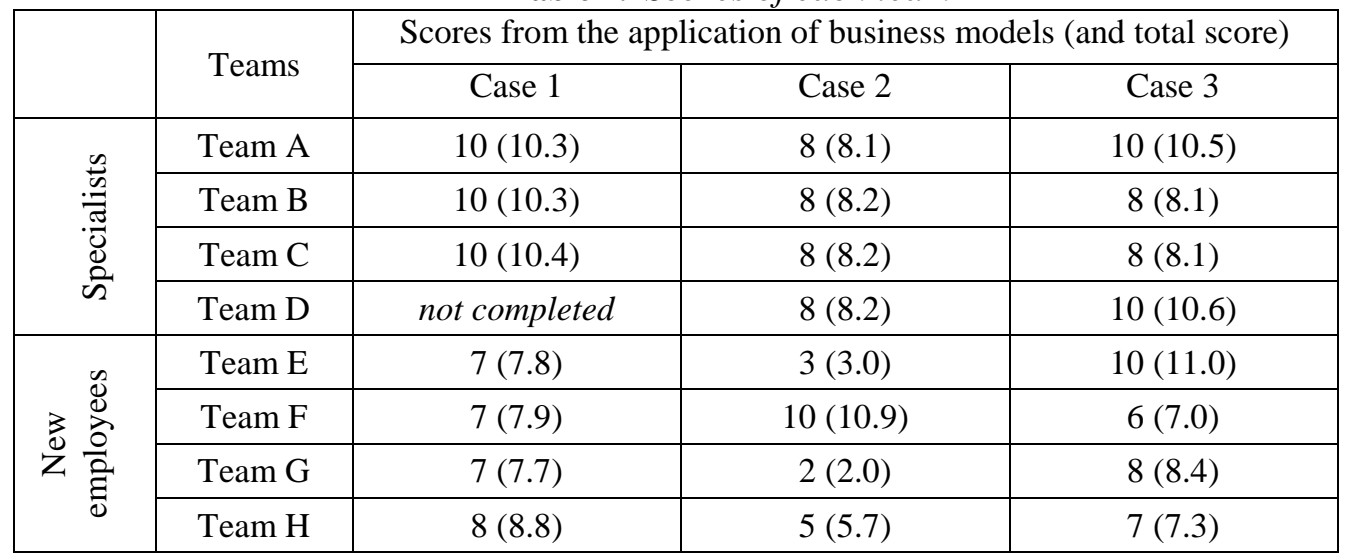


Three teams of experienced specialists got all possible 10 points for choosing the right business model in case 1 . The perfect score can be explained by the introduction nature of the case where the business model was the same as a strategy that the organisation used prior to the new business models. One team did not complete their work on time due to a misunderstanding of the rules. At the same time, they got $0.3,0.3$ and 0.4 extra points for changes based on the strategic plan of the organisation. Three teams of new employees had 7 points by having 3 out of 5 elements of the business model correct and one element partly correct. They chose partially the right compensation form, and they chose the wrong awarding criteria. One team of new employees had 8 points because they chose the wrong awarding criteria. These teams got $0.8,0.9,0.7$ and 0.8 extra points for trying to think extra about the strategic goals of the organisation.

During the second case, all teams of specialists scored 8 points based on their choice of business strategy. All teams had selected the wrong contract form that emphasised on functional requirements instead of emphasising on performance requirements. This change in the contract form was one of the few elements of the new business models. The teams got an extra $0.1,0.2,0.2$ and 0.2 points for additional changes. The teams of new employees scored 3 points, 10 points, 2 points, and 5 points. The variety in the answers is related to the background of the participants. The biggest challenges were the contract form, awarding criteria and procurement procedure. Two of these teams did not get any extra points, one team scored 0.7 extra points and the second received 0.9 extra points.

Two teams of experienced specialists got 10 points and two other teams got 8 points for the right business models during the last case. One team had the wrong contract form, and another team had the wrong procurement procedure. These teams also got $0.1,0.1$, 0.5 and 0.6 extra points.

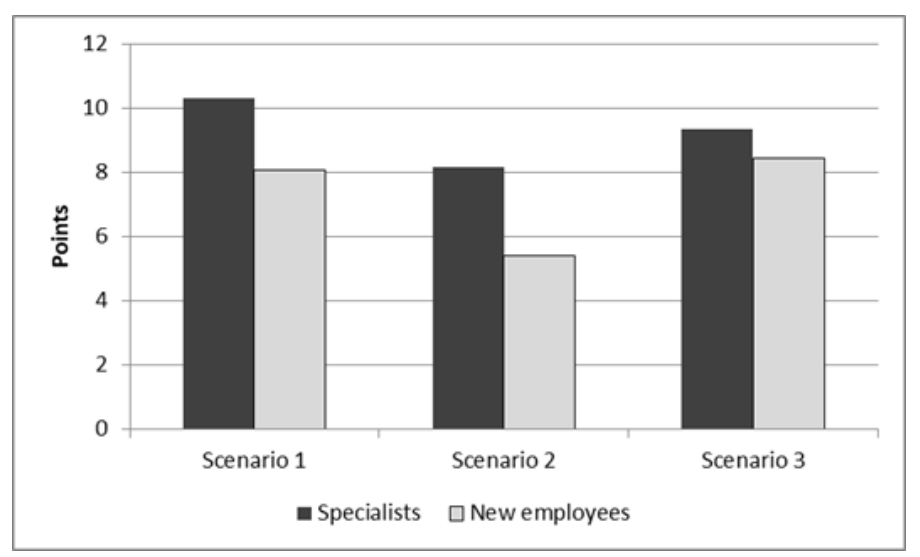

Figure 2. Average points for each case

Despite the variations in the teams, the teams of high-level specialists had higher scores than the new employees, as seen in Figure 2. The highest results in case 1 can be explained by the business models for procurement for road designing existing already previously for several years. The lower scores for road construction procurement could be explained by the high level of complexity in road construction projects in general. Also, new business models suggested using a different contract form for road construction procurement, which contributed to lower scores in case 2.

\subsection{Extra points}

The lesser total points scored by the less experienced teams were understandable and even expected. However, in each case the teams of new employees received more extra points compared to the experienced teams. Figure 3 shows only the extra points that the teams received during the game. The less experienced teams in each case had more than double 
pag. 32

the points for creative thinking to incorporate the strategic goals of the organisation in their work.

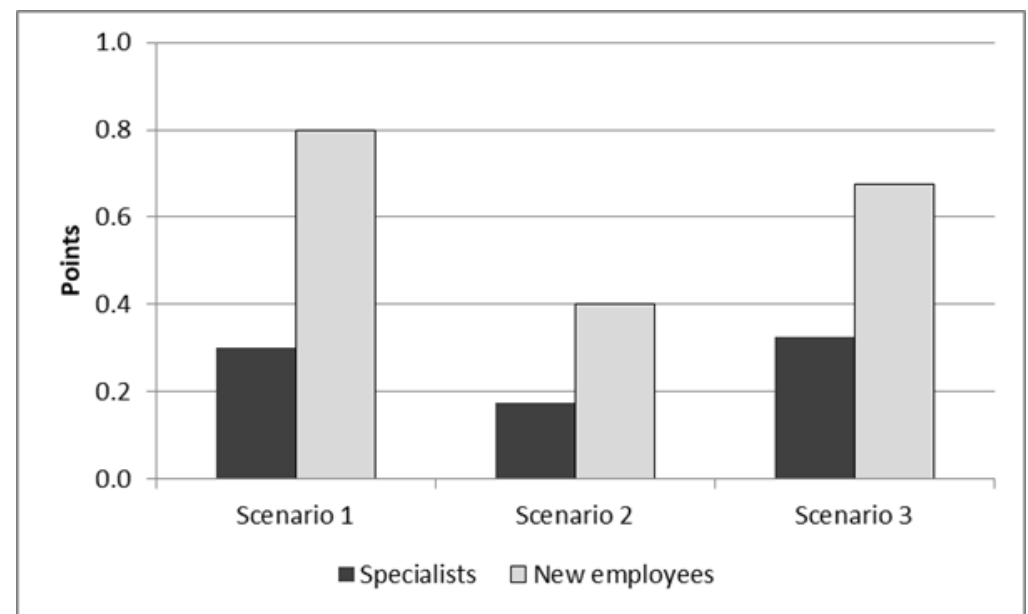

Figure 3. Average points for implementing general strategies of the organisation for each case

Another important aspect is to see the scored points compared to the maximum possible points. Figure 4 shows how the specialists and new employees scored based on the application of the business model and also based on extra changes compared to the maximum for each category.

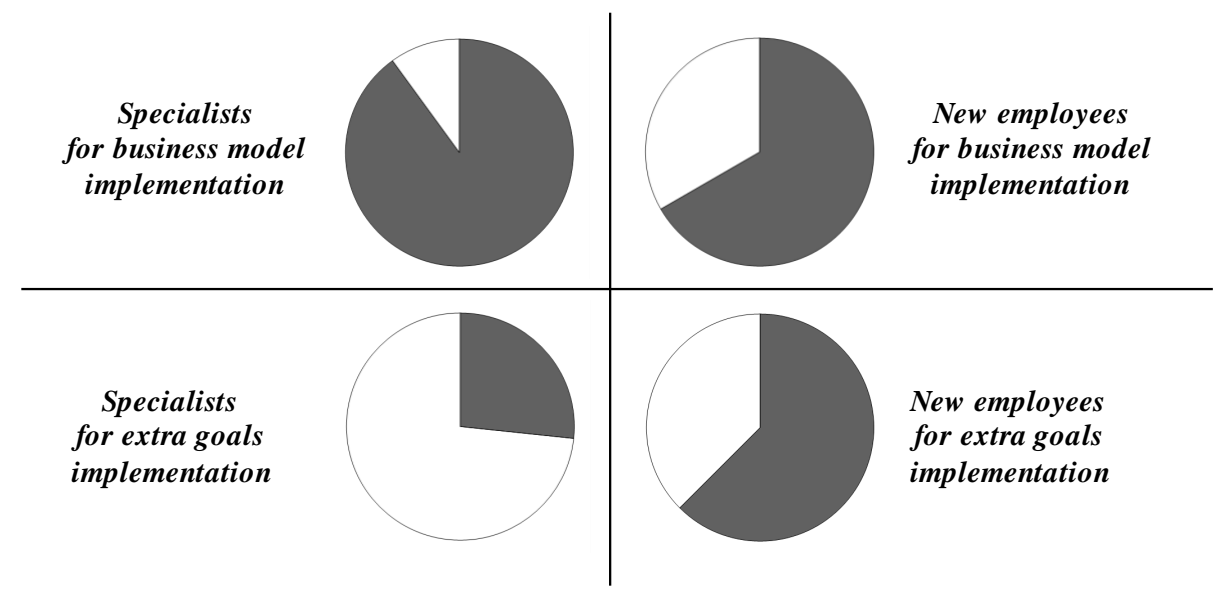

Figure 4. Average points gained by the teams compared to the maximum possible score

It can be seen in Figure 4 that new employees were consistent in their performance, scoring about $2 / 3$ of the possible points. The missing one-third points can be explained by their lack of experience and thus a full understanding of all aspects of the working reality.

However, there is a big difference in the results of the teams of experienced specialists. The high results in the application of business models can be explained by their better understanding of the situation and knowing what to look for in the provided documentation. But at the same time, this experience can be a blockage for thinking outside the typical boundaries. The lesser points for extra work in implementing general strategies of the organisation do not indicate that participants did not know how to apply them. Instead, it shows that when implementation of general strategies is not the main focus of the exercise or work, experienced employees tend to ignore strategic goals and 
focus on main operational or tactical tasks, which is a valid representation of how work is done in a real system as well.

\subsection{Understanding of business models}

When participants were asked to reflect on training about business models, most of the feedback was not about how to implement a model, but rather how to identify which is the right model for each case. Currently, identification of the right model depends on an accurate evaluation of the level of complexity, the degree of freedom and the level of uncertainties; but these aspects are not well-defined in the documentation and are not binary. Even more, rather than being a single aspect, each of them is more a cluster of different sub-aspects. For instance, the level of complexity depends on how many people or resources from the organisation are available to control the process. The main subaspects can be seen in Table 3 based on the feedback from participants. These sub-aspects were mentioned to have the highest effect on each of the aspects of the business models.

Table 3. Sub-aspects for each aspect of business model identification

\begin{tabular}{|c|c|c|}
\hline Level of Complexity & Degree of Freedom & Level of Uncertainty \\
\hline $\begin{array}{l}\text { Number of people involved in } \\
\text { the process }\end{array}$ & $\begin{array}{l}\text { Freedom to use technical } \\
\text { solutions }\end{array}$ & $\begin{array}{l}\text { Knowledge of the geological } \\
\text { area }\end{array}$ \\
\hline $\begin{array}{l}\text { Number of resources involved } \\
\text { in the process }\end{array}$ & Freedom in the work field & $\begin{array}{l}\text { Knowledge of the } \\
\text { archaeological area }\end{array}$ \\
\hline Holism of entire project & specifications & $\begin{array}{l}\text { Knowledge of meteorological } \\
\text { conditions }\end{array}$ \\
\hline $\begin{array}{l}\text { Number of interested } \\
\text { stakeholders }\end{array}$ & $\begin{array}{l}\text { Number of functional } \\
\text { specifications }\end{array}$ & $\begin{array}{l}\text { Communication procedures } \\
\text { between the buyer and }\end{array}$ \\
\hline $\begin{array}{l}\text { Political influence on the } \\
\text { project }\end{array}$ & Changes in the legal system & suppliers \\
\hline Technical complexity & Changes in norms & Working environment \\
\hline Risk level & & \\
\hline Market situation & & \\
\hline Size of the project & & \\
\hline
\end{tabular}

It is essential to understand better all aspects to make the right decision. Breaking each aspect into sub-aspects helps to evaluate projects and be more precise in decision making.

\section{Discussion}

Gamifying the steps for preparation for change, such as training for new procurement processes, creates a safe environment for the organisation that allows learning about changes in a creative way and having open conversations to have smooth real-life applications.

This work focused on gamification of training for road procurement. Three parts had to be achieved to ensure that this gamification was successful: proper gamification of the design and operation of the procurement process, cultivating a game culture in the organisation, and proper gamification of the training with a proper training needs 
assessment. A process for gamification of training for procurement was designed for this purpose. This process was described and applied to develop training for employees working with the procurement process.

Gamification of the procurement process was performed based on an existing process with the scope of the procurement specialist. All actions, information flow and other elements of the system that affected the procurement specialist were preserved, providing credibility and reliability of the final solution.

Gamification of training was used with procurement specialists and newly hired employees to work with procurement in the Swedish Transport Administration. Three cases were developed based on three main types of contracts, and the training aimed to teach how to implement better the new business models that the organisation had developed.

The more experienced procurement specialists had better results compared to the new employees in applying business models because of a better understanding of the level of complexity, the degree of freedom and the level of uncertainty in projects; but at the same time, the new employees showed better results in applying the strategic goals of the organisation to promote innovation, transparency, sustainability, life-cycle costs, etc. It can be explained that specialists are trained more to focus on primary operation tasks, which was the application of business models, even if it means sacrificing everything that is not related to this operation level work.

Another output from the training was that a problem was not in the application of the model, but rather in understanding aspects related to decision making. Players mentioned that most of them had no issues with including all elements from business models in their work, but the challenge was to determine which business model suited each case better. The problem arose from the fact that the criteria for choosing the proper model were fuzzy and often it was not obvious what the right choice was. Hence, a lot of discussions were focused on what the complexity, freedom and uncertainties were in the projects. Gamification of the training allowed players to understand better how these criteria affected their final results by providing immediate feedback to information that was impossible in the real world.

This gamification of training was for specific projects; nevertheless, the lessons obtained in this training are of current interest for many units of the organisation. The successful outcome of this training increased the desire of the organisation to use this gamification in training in future with new employees and to apply gamification when training on other important issues like the life-cycle perspective, communication with external stakeholders, use of bonus systems, etc.

Although this work had a small participant sample, gamification still provided sufficient results that can be generalised. The training was limited to only sixteen people because of the requirement for the knowledge and experience that participants had to have; and notwithstanding that the gamification of training was for procurement in the road construction sector, the results of this work can be related to purchasing policies in many different sectors.

The first lesson is that the procurement process can be gamified in a holistic manner despite all its complexity. It requires knowing which aspects and which stakeholders are essential to include in the gamification design, but it is possible to 'play' with procurement even for more complicated tasks.

The second lesson is that employees with years of experience will have different results compared to employees with less experience. Although this experience helps to have better performance of the main task, the experience of employees can be damaging to creativity. Since experience works based on specific patterns and situations, it becomes harder to break such patterns and to think outside the box. It is not necessarily an issue that experience lacks creativity, because it helps to focus on primary tasks and maintain order, especially in hierarchical organisations; but it is something that policymakers need to be aware of and to choose a proper balance between the widening scope of works to 
include strategic vision and deepening work processes to improve the quality of individual tasks.

The last, but not least, lesson is that in gamification of training it is always important to identify issues accurately and to determine the nature of the problem in complex and adaptive environments. Assessing the needs for training can help to see if the issue is about how to apply a solution or rather how to understand and choose the right one. Therefore, if there is a need to implement a new solution, procedure or model, the question must be about whether there will be a problem with this implementation process or rather with the necessary experience to apply and understand the aspects of such implementation.

\section{Conclusion}

The project procurement process in public organisations is a complex process that is hard to train holistically with traditional tools. However, it can be done by using gamification for specific purposes, such as behaviour observation or training. A case of gamification of training for employees, who worked in procurement in the road construction sector, was presented. To make sure that this gamification was successful, it was important to have proper gamification of the procurement process, an organisation that was prepared for the gamified approach and gamification of training that was designed to address appropriate training needs.

A process for gamification of training for procurement was designed for this purpose. This was done based on original templates and standard documents that were used by the organisation. It was important to include all complex elements that existed in the projects and between organisations. Three elements were observed during the gamification to evaluate the game: total scores, the ability to implement the strategic goals of the organisation, and aspects that contribute to decision making.

The results were analysed and from the analysis, it can be concluded that gamification of the procurement process was possible, and gamification of professional training can be applied for the procurement process. This gives an opportunity for employees working in procurement to see a better connection between aspects of decision making and the results of the procurement process.

The findings in this work show that gamification of training helps to address the needs of the organisation and participants in obtaining and applying new knowledge. These findings also help to see the difference between experienced purchasing specialists and new employees. It signifies that although experience is vital to fulfil primary work, experienced employees often miss opportunities to include strategic vision in their work.

Another finding shows the importance of aspects related to the complexity of the real system and how these aspects affect the results of gamification. It emphasised a need for better understanding and defying such aspects.

Although these results were obtained from the road construction sector, these findings can be applied to the majority of public service organisations that use project procurement in their work. This is because procurement processes for most of these cases are complex and need to be addressed, considering the social and technical parts together.

\section{References}

[1] United Nations, "Procurement Practitioner's Handbook," 2017.

[2] P. Baily, D. Farmer, B. Crocker, D. Jessop, D. Jones, Procurement Principles and Management, 10th ed. New York: Prentice Hall Financial Times, 2008.

[3] G. D. Holt, "Classifying construction contractors," Build. Res. Inf., vol. 25, no. 6, pp. 374382, Nov. 1997. https://doi.org/10.1080/096132197370200 
[4] S. Rowlinson, P. McDermott, Procurement Systems: A Guide to Best Practice in Construction. Routledge, 2005.

[5] M. C. B. de Araújo, L. H. Alencar, C. M. de Miranda Mota, "Project procurement management: A structured literature review," Int. J. Proj. Manag., vol. 35, no. 3, pp. 353-377, Apr. 2017. https://doi.org/10.1016/j.ijproman.2017.01.008

[6] M. Eriksson, "Procurement of Complex Technical Systems: Strategies for Successful Projects," DIVA, 2005.

[7] E. Uyarra, J. Edler, J. Garcia-Estevez, L. Georghiou, J. Yeow, "Barriers to innovation through public procurement: A supplier perspective," Technovation, vol. 34, no. 10, pp. 631-645, Oct. 2014. https://doi.org/10.1016/j.technovation.2014.04.003

[8] S. A. Hazlett, R. Mcadam, V. Beggs, "An exploratory study of knowledge flows: A case study of Public Sector Procurement,” Total Qual. Manag. Bus. Excell., vol. 19, no. 1-2, pp. 57-66, Feb. 2008. https://doi.org/10.1080/14783360701602205

[9] R.-J. Dzeng, K.-Y. Lin, P.-R. Wang, "Building a construction procurement negotiation training game model: Learning experiences and outcomes,” Br. J. Educ. Technol., vol. 45, no. 6, pp. 1115-1135, Nov. 2014. https://doi.org/10.1111/bjet.12189

[10] M. Regan, J. Smith, P. Love, "Infrastructure Procurement: Learning from Private-Public Partnership Experiences 'Down Under," Environ. Plan. C Gov. Policy, vol. 29, no. 2, pp. 363-378, Apr. 2011. https://doi.org/10.1068/c10122b

[11] A. Badanidiyuru, R. Kleinberg, Y. Singer, "Learning on a Budget: Posted Price Mechanisms for Online Procurement," in Proceedings of the 13th ACM Conference on Electronic Commerce, New York, NY, USA, 2012, pp. 128-145. https://doi.org/10.1145/2229012.2229026

[12] M. Kornevs, N. Kringos, S. Meijer, "A research agenda for green procurement of infrastructures," in 2014 International ICE Conference on Engineering, Technology and Innovation (ICE), 2014, pp. 1-7. https://doi.org/10.1109/ICE.2014.6871604

[13] European Commission, "International public procurement European Commission," Growth. [Online]. Available: /growth/single-market/public-procurement/international_en. [Accessed: 06-Mar-2017].

[14] A. Erridge, R. Nondi, "Public procurement, competition and partnership," Eur. J. Purch. Supply Manag., vol. 1, no. 3, pp. 169-179, 1994. https://doi.org/10.1016/09697012(94)90006-X

[15] P. E. Eriksson, "Procurement Effects on Coopetition in Client-Contractor Relationships," J. of Construction Eng. and Manag., vol. 134, no. 2, pp. 103-111, 2008. https://doi.org/10.1061/(ASCE)0733-9364(2008)134:2(103)

[16] L. S. Pheng, "Project Procurement Management," in: Project Management for the Built Environment, Springer, Singapore, 2018. https://doi.org/10.1007/978-981-10-6992-5

[17] D. Walker, K. Hampson, "Procurement Strategies: A Relationship-based Approach," John Wiley \& Sons, 2008.

[18] R. Watermeyer, "Changing the construction procurement culture to improve project outcomes," Joint CIB W, 2012.

[19] D. Prajogo, J. Olhager, "Supply chain integration and performance: The effects of long-term relationships, information technology and sharing, and logistics integration," Int. J. Prod. Econ., vol. 135, no. 1, pp. 514-522, Jan. 2012. https://doi.org/10.1016/j.ijpe.2011.09.001

[20] M. Kornevs, "Assessment of Application of Participatory Methods for Complex Adaptive Systems in the Public Sector," Stockholm, Sweden, 2019.

[21] M. Kornevs, J. B. Hauge, S. Meijer, "Perceptions of stakeholders in project procurement for road construction," Cogent Bus. Manag., vol. 0, no. ja, p. null, Sep. 2018. https://doi.org/10.1080/23311975.2018.1520447

[22] S. Tadelis, "Public procurement design: Lessons from the private sector," Int. J. Ind. Organ., vol. 30, no. 3, pp. 297-302, May 2012. https://doi.org/10.1016/j.ijindorg.2012.02.002

[23] S. Baldi, A. Bottasso, M. Conti, C. Piccardo, "To bid or not to bid: That is the question: Public procurement, project complexity and corruption," Eur. J. Polit. Econ., vol. 43, pp. 89106, Jun. 2016. https://doi.org/10.1016/j.ejpoleco.2016.04.002

[24] E. Uyarra, K. Flanagan, "Understanding the Innovation Impacts of Public Procurement," Eur. Plan. Stud., vol. 18, no. 1, pp. 123-143, Jan. 2010. https://doi.org/10.1080/09654310903343567

[25] V. M. Shreenath, M. Kornevs, J. Raghothama, S. Meijer, "A Feasibility Study for Gamification in Transport Maintenance: Requirements to Implement Gamification in Heterogeneous Organizations," in 2015 7th International Conference on Games and Virtual 
Worlds for Serious Applications (VS-Games), 2015, pp. 1-7. https://doi.org/10.1109/VSGAMES.2015.7295758

[26] R. N. Landers, E. M. Auer, A. B. Collmus, M. B. Armstrong, "Gamification Science, Its History and Future: Definitions and a Research Agenda," Simul. Gaming, vol. 49, no. 3, pp. 315-337, Jun. 2018. https://doi.org/10.1177/1046878118774385

[27] K. Seaborn, D. I. Fels, "Gamification in theory and action: A survey," Int. J. Hum.-Comput. Stud., vol. 74, pp. 14-31, Feb. 2015. https://doi.org/10.1016/j.ijhcs.2014.09.006

[28] S. Deterding, D. Dixon, R. Khaled, L. Nacke, "From Game Design Elements to Gamefulness: Defining "Gamification," in Proceedings of the 15th International Academic MindTrek Conference: Envisioning Future Media Environments, New York, NY, USA, 2011, pp. 9-15. https://doi.org/10.1145/2181037.2181040

[29] K. Robson, K. Plangger, J. H. Kietzmann, I. McCarthy, L. Pitt, "Is it all a game? Understanding the principles of gamification,” Bus. Horiz., vol. 58, no. 4, pp. 411-420, Jul. 2015. https://doi.org/10.1016/j.bushor.2015.03.006

[30] R. N. Landers, "Developing a Theory of Gamified Learning: Linking Serious Games and Gamification of Learning," Simul. Gaming, vol. 45, no. 6, pp. 752-768, Dec. 2014. https://doi.org/10.1177/1046878114563660

[31] S. Nicholson, "A RECIPE for Meaningful Gamification," in Gamification in Education and Business, T. Reiners and L. C. Wood, Eds. Cham: Springer International Publishing, 2015, pp. 1-20. https://doi.org/10.1007/978-3-319-10208-5 1

[32] R. N. Landers, K. N. Bauer, R. C. Callan, M. B. Armstrong, "Psychological Theory and the Gamification of Learning," in Gamification in Education and Business, T. Reiners and L. C. Wood, Eds. Cham: Springer International Publishing, 2015, pp. 165-186. https://doi.org/10.1007/978-3-319-10208-5_9

[33] B. Burke, Gamify: How Gamification Motivates People to Do Extraordinary Things. Routledge, 2016. https://doi.org/10.4324/9781315230344

[34] I. Bogost, "Gamification Is Bullshit," The Atlantic, Aug. 2011.

[35] Ahmed El-Khuffash, "Gamification," Ryerson University, Torondo, Canada, 2013.

[36] A. Alexandrova, L. Rapanotti, I. Horrocks, "RE-PROVO: An Evaluation of Gamification in a Law Enforcement Organization," in Proceedings of the Workshop on Fictional Game Elements, 2016, p. 8.

[37] E. A. Surface, "Training needs assessment: Aligning learning and capability with performance requirements and organizational objectives," in The handbook of work analysis: Methods, systems, applications and science of work measurement in organizations, New York, NY, US: Routledge/Taylor \& Francis Group, 2012, pp. 437-462.

[38] P. Eriksson, J. Hane, "Entreprenadupphandlingar - Hur kan byggherrar främja effektivitet och innovation genom lämpliga upphandlingsstrategier? (Contracting Procurement - How can builders promote efficiency and innovation through appropriate procurement strategies?)," Konkurrensverket, 2014. 